\title{
OS CONTRATOS DE EMPREITADA E A APLICAÇĀO DA CLÁUSULA "REBUS SIC STANTIBUS" NO DIREITO ADMINISTRATIVO
}

\author{
OSCAR SARATVA \\ Consultor Jurídico do Ministério do \\ Trabalho, Indústria e Comércio

\begin{abstract}
SUMÁRIO : Efeitos da guerra sôbre o valor da moeda - Natureza dos contratos administrativos - Prazo de duração do contrato - Empreitada - $O$ art. 1.238 do Código Civil - Alterações substanciais - Diretrizes a observar.
\end{abstract}

1. A guerra mundial que assolou o mundo civilizado de $\mathbf{1 9 1 4}$ a 1918 e que hoje, por fôrça da repetição dêsse flagelo em maior escala, é conhecida como a primeira grande Guerra, entre os fenômenos jurídicos que determinou, trouxe consigo a revivescência da velha doutrina da cláusula rebus sic stantibus, nos têrmos da qual as obrigações estipuladas em um contrato se entendiam vinculadas à permanência das condições que vigoravam ao tempo de sua celebração, e, alteradas estas, modificavam-se correlatamente os encargos ccntratuais.

2. E a exumação da velha teoria era de manifesta oportunidade. Contratos celebrados antes da catástrofe social difícilmente poderiam encontrar aplicação se fôssem atendidos os têrmos do que fôra pactuado. Também se não se admitisse a modificação de encargos ou obrigações assumidas conformando-os às novas condições vigentes, sofreria uma das partes lesão enormíssima, enquanto a outra se veria beneficiada com um verdadeiro enriquecimento sem causa justa. Assim, para apontarmos apenas uma hipótese, os casos de mútuos hipotecários, celebrados antes da desvalorização monetária ocorrida na Europa Central, em que, a prevalecerem os têrmos primitivos, o credor receberia em pagamento moeda de tal sorte desvalorizada que aquêle que houvesse emprestado, antes da guerra, quantia de vulto, receberia de seu devedor, alguns anos depois, soma sujo valor real já não bastaria para adquirir uma caixa de fósforos. 
O mesmo fenômeno ocorre agora na Grécia recém-libertada, onde a desvalorização monetária tem alcançado proporções de difícil expressão numérica, segundo os mais recentes noticiários.

3. Dêsse repentino desajustamento dos fatos da vida social surgia, portanto, como conseqüência inevitável, a necessidade imperiosa de uma adaptação das teorias jurídicas aos seus novos aspectos, de molde a restabelecer o indispensável e justo equilíbrio entre os interessados em contratos bilaterais, resguardando-se o patrimônio de ambos e atendendo ao fim último do direito como regra da conduta humana em sociedade, ó que ainda se cifra no preceito comano do suum cuique tribuere. Para resolver êsse conflito, buscou-se, como meio prático, a velha ressalva, cuja justificativa, na atualidade, ninguém melhor do que RENÉ DEMOGUE soube dar :

"Au point de vue social, les contrats sont moins des générateurs de droits individuels et individualistes dans leurs fins que des combinaisons protégées par la loi pour arriver à des fins supérieurs: création, distribution des richesses pour la satisfaction des êtres humains. Par le contrat, les personnes s'associent pour leur intérêt commun.

En face des circonstances nouvelles il faut le répéter: le contrat qui est chase vivante ne peut être absolument rigide. Vivre, c'est se transformer en restant dans une certaine direction générale. La révision du contrat simpose donc." 1

4. Entre nós, essa doutrina é hoje sustentada por vários juristas de escol. Assim é que ARnoldo MEdeiros da Fonseca, professor de Direito Civil da Faculdade de Direito da Universidade do Rio de Janeiro, depois de estudá-la longamente em sua excelente monografia Caso Fortuito e Teoria da Imprevisão, conclui declarando que :

"Somos assim levados a reconhecer que, presentemente, em face dos princípios que resultam da legislação vigente, a superveniência de acontecimentos imprevistos e imprevisíveis alterando radicalmente o ambiente objetivo existente ao tempo da formação do contrato e acarretando para um dos contratantes uma onerosidade excessiva e não compensada, por outras vantagens auferidas anteriormente, ou ainda esperáveis, diante dos têrmos do ajuste, pode dar lugar à intervenção judicial para resolver o vínculo contratual. Para isso, porém, exige que, às duas primeiras condições, acima fixadas, se alie uma terceira : o lucro inesperado e injusto do credor, excedente a um quinto do valor normal da prestação a que teria

1 Rene Demogue, Traité des Obligatione en ánéral, tome VI, Paris, 1931, pág. 697. 
direito, limite êsse estabelecido em disposições análogas de nosso direito positivo". 2

5. Por sua vez, o ilustre jurisconsulto Eduardo Espínola, Ministro e Presidente do Supremo Tribunal Federal, examinando o assunto, conclui pela possibilidade de revisão contratual em casos especiais, ficando "aberto ao exame e à interpretação dos tribunais se, dos princípios gerais de direito em que se inspira a nossa legislação comum, resulta que se deve reconhecer a teoria da imprevisāo e amparar a parte obrigada com fundamento na cláusula rebus sic stantibus em casos imprevistos de excepcional gravidade, em que o cumprimento de sua prestação se transforma em insuportável sacrifício e fragosa injustiça". ${ }^{3}$

$E$ invoca o eminente magistrado o ponto de vista jurisprudencial brasileiro, segundo o acórdão do egrégio Supremo Tribunal Federal de 22 de novembro de 1938, em que essa alta côrte de justiça, por maioria de votos, não tomou conhecimento do recurso extraordinário interposto da decisão do Tribunal de Apelação do Distrito Federal que, no julgamento de causa subordinada a seu exame, acolheu em favor daquele que a invocou a cláusula rebus sic stantibus.

6. No Direito Administrativo, mais que no Direito Civil, há maior margem para a admissão da revisão contratual sob a pressão de novas condições econômicas. Se, via de regra, os contratos de direito civil se executam num ambiente limitado e em tempo restrito, os contratos de Direito Administrativo se dilatam, em seu exercício, no tempo e no espaço, sofrendo mais, e por isso mesmo, as variações inerentes às mutações sociais : "... o direito administrativo está ligado de forma íntima à vida social e política de um povo. $\mathbf{E}$ os contratos administrativos constituem uma das mais importantes manifestações da atividade administrativa. Mas não se lhes poderia rodear a celebração de garantias tão minuciosas e precisas que regulassem tôdas as modalidades permissíveis da sua execução. Celebrados em tempos normais, pela forma legal, como thes exigir o cumprimento em situações anormais tais como a revolução e a guerra?" 4

Por isso, se é assegurada ao Poder Público a revisão contratual, se, conforme observa BERTHÉLEMY, 5 “... o contrato não se

2 Pág. 332, n.0 241.

3 Direito, vol. I, pág. $34-A$ cläusula "rebus sic stantibus" no direito contem porâneo.

4 Tavares de LiRa Filho, Contratos Administrativos, Rio, 1941, pág. 168.

5. Cf. TAvares de Lira Filho, ob. cit. 
executa sempre tal como foi assinado, se a "administração tem o direito de fazer modificações desde que não o desnature", resulta também, como corolário juridico, que ao contratante caberá igualmente pleitear a revisão quando as circunstâncias o autorizam a tanto. Aliás, essa reciprocidade é prevista e assegurada entre nós pelo texto constitucional, no que concerne ao custo dos serviços públicos explorados mediante concessão, dispondo o art. 147 da Carta de 10 de novembro que :

"A lei federal regulará a fiscalização e revisão das tarifas dos serviços públicos explorados por concessão para que, no interêsse coletivo, delas retire o capital uma retribuição justa ou adequada e sejam atendidas convenientemente as exigências de expansão e melhoramentos dos serviços.

A lei se aplicará às concessões feitas no regime anterior de tarifas contratualmente estipuladas para todo o tempo de duração do contrato".

7. Assim, pois, em se tratando de contratos administrativos a longo prazo, cuja prestação se dilatar por espaçado período, tal como as concessōes de serviço público, não ocorre dúvida em que se possa operar a revisão, reajustando-se os preços aos valores correntes. Para êsses contratos, o legislador constitucional assegurou a faculdade da revisão, a ser pleiteada pelos interessados, de forma a permitir que durante tôda a sua vigência se mantenha 0 equilíbrio entre as obrigações assumidas pelos contratantes e os direitos que lhes devem ser assegurados.

8. Restará indagar, porém, se nos contratos a breve tempo, como os de empreitada, há margem para a revisăo, e se teria cabimento e aplicação a teoria da superveniência para justificar majorações de preço.

9. Aí o problema assume aspecto diverso, havendo que considerar como fatôres relevantes não os prazos limitados que caracterizam êsses contratos, como ainda a sua própria natureza aleatória, segundo a regra do art. 1.238 do Código Civil :

"Quando o empreiteiro fornece os materiais, correm por sua conta os riscos até o momento da entrega da obra..."

10. Em verdade, se é difícil prever as mutações econômicas em relação a futuro remoto, essa conjectura já é possível com referência a épocas próximas ou imediatas, dentro de limites razoáveis, e só excepcionalmente é que a mutação pode ser de tal modo brusca 
e violenta que autorize, pelo seu caráter de manifesta fôrça maior, a alteração ou a rescisão do contrato.

11. Em face dêsses fatos, poderemos inferir duas conseqüências de manifesta importância e que, ao nosso ver, devem constituir as normas inspiradoras do tratamento a ser dispensado aos empreiteiros de obras públicas. A primeira é a de que: as flutuaçóes econômicas e as alterações de mercados não devem constituir normalmente motivo para que sejam pleiteadas alterações contratuais ou majorações de preços.

E a segunda, que lhe é correlata, se pode traduzir no reconhecimento de que : sòmente a mutação inesperada e violenta das condições econômicas e sociais, trazendo consigo a característica de verdadeira fôrça maior, é que poderá jưstificar alterações nas condições do TEMPo ou de cusTo dos contratados de empreitada.

12. Assim, ao contratar a execução de determinada obra com o Estado ou com as entidades dêste delegadas, obra que deve estar concluída em período relativamente breve, o empreiteiro deverá prever, desde logo, as condições que irá enfrentar a fim de conseguir, para o serviço a realizar, a mão-de-obra e o material indispensável. $O$ custo da mão-de-obra e do material e a possibilidade de obtê-los são fatôres que devem ser prèviamente ponderados dentro da previsibilidade das condições da vida humana, considerando-se a possibilidade dó encarecimento da mão-de-obra ou da elevação do custo de materiais, ou dos fenômenos inversos, ou seja a baixa do preço, quer do material, quer da mão-de-obra. Esse motivo, aliás, é que faz com que o contrato de empreitada, na forma do art. 1.238 transcrito do Código Civil, seja considerado aleatório, cabendo ao empreiteiro os riscos do maior ou menor lucro, e mesmo dos prejuízos que possa sofrer, se não guardou êle, em suas conjecturas, a segurança ou a prudência necessárias.

13. Se, entretanto, fora do campo de previsibilidade das coisas humanas, surgem fatôres que obstam, como verdadeiros motivos de fôrça maior, no sentido amplo da expressão, à execução da obra, seja pela impossibilidade de obter o empreiteiro material indispensável, seja pela falta absoluta da mão-de-obra, nesses casos não seria justo nem eqüitativo que, sob a pressão dessas condições sociais supervenientes, prevalecessem as cláusulas de prazo ou de preço ajustadas em condições diversas, dado que o Estado, tal como o particular, não se deve prevalecer de um ajuste para exigir uma obra em prazo impossivel ou por preço manifestamente desproporcionado aos valores do momento em que a recebe. Nesses casos, impõe-se a revisão contratual, para que não sofra o contratante conseqüências im- 
previsiveis e que the trariam maiores prejuízos que aquêles que devem ser normalmente suportados .

14. Do exposto, resulta como diferença substancial entre os contratos que envolvem obrigação de fazer a longo prazo e aquêles em que essas obrigações se cumpram em curto prazo, que em relação aos primeiros a revisão se pode operar pelo simples transcurso do tempo, e que as transformações normais das condições econômicas podem justificar, ao fim de certo período, a revisão de suas cláusulas, ao passo que nos contratos a breve têrmo essa revisão só se justificará em face de ocorrências que escapam à previsão normal dos contratos. Diante dêsses critérios gerais, caberá ao administrador orientar-se, indagando, em relação a cada caso concreto, se ocorreram ou não fenômenos imprevisíveis cuja verificação haja alterado substancialmente as condições do contrato.

15. Dir-se-á que a questão continua em aberto, desde que a conceituação dos fenômenos referidos estaria ainda por fazer. Sob êsse aspecto, porém, julgamos insuscetiveis de classificação prévia as situações sociais que podem repercutir nas obrigaçōes de fazer, dificultando-lhes o cumprimento no prazo ou tornando sua execução de tal sorte onerosa que êsse cumprimento nas condições pactuadas acarretaria a ruína do contratante. Nem bastaria o apêlo às figuras clássicas do caso fortuito e da fôrça maior: a guerra, por exemplo, pode trazer efetivo impedimento ao cumprimento de uma obrigação ou pode ser mero pretexto para um inadimplemento injustificado.

16. Fixadas, pois, semelhantes diretrizes, o que caberá, em cada caso, é o exame atento dos fatos, indagando-se da natureza e das condições das transformações ocorridas, para que, segundo as circunstâncias, sejam ou não autorizadas as correspondentes modificações. 